\title{
BENEFÍCIOS FISCAIS DECLARADOS INCONSTITUCIONAIS E OS REFLEXOS ECONÔMICOS E JURÍDICOS
}

Lucas Pires Maciel*

Marisa Rossignoli**

SUMÁRIO: Introdução; 2 Direito e Economia; 3 A Extrafiscalidade do Tributo; 4 Os Benefícios Fiscais; 5 Benefícios Fiscais Declarados Inconstitucionais e os Efeitos Jurídicos Econômicos; 6 Considerações Finais; Referências.

RESUMO: O artigo tem como escopo estudar os efeitos jurídicos e econômicos na ocasião em que o Supremo Tribunal Federal declara um benefício fiscal inconstitucional. Para a realização do estudo iniciou-se enunciando as ciências que interferem no presente caso, o Direito e a Economia. Viu-se que são ciências independentes nos seus méritos, porém com íntima relação, haja vista a sua interdisciplinaridade. Tratou sobre a extrafiscalidade dos tributos e a sua importância na economia. Abordou o Direito ao Desenvolvimento e as características que devem nortear essa extrafiscalidade. Ademais, tratou dos benefícios fiscais, como forma de incentivar a economia e os meios utilizados pelos entes tributantes para desoneração tributária. Apresentou os efeitos jurídicos e econômicos de benefícios declarados inconstitucionais e enfatizando a possibilidade ou não de o fisco exigir o principal e multa dos contribuintes que gozaram desses benefícios considerados inconstitucionais. Para elaboração do artigo utilizou-se o método dedutivo com pesquisas bibliográficas.

PALAVRAS-CHAVE: Benefício Fiscal; Direito; Economia; Extrafiscalidade; Inconstitucionalidade.

\section{NON-CONSTITUTIONAL FISCAL BENEFITS AND ECONOMICAL AND JURIDICAL CONSEQUENCES}

ABSTRACT: Current paper analyzes the juridical and economic effects when the Higher Courts declares non-constitutional a fiscal benefit. In the first place, Law and Economy are the two sciences that intervene in current issue. They are independent sciences in their own right, but closely relatedly due to interdisciplinarity. The extra-fiscality of taxes and their importance in the economy are discussed, through the right to development and the characteristics that should guide extra-fiscality. Fiscal benefits are ways that enhance the economy and the means used by tax authorities to

\footnotetext{
Advogado. Doutorando em Direito da Universidade de Marília (UNIMAR), São Paulo, Brasil. Docente do Centro Universitário Toledo de Presidente Prudente, São Paulo, Brasil.

** Docente Dra. no Programa de Mestrado e Doutorado em Direito Universidade de Marília (UNIMAR), São Paulo, Brasil. E-mail: mrossignoli@unimar.br
} 
unburden the economy. The juridical and economic effects of benefits which were declared unconstitutional were presented and the possibility that the tax authority demands the principal plus fine from contributors benefitted were underscored. The deductive method with bibliographical research work was employed.

KEY WORDS: Fiscal benefits; Law; Economy; Extra-fiscal; Non-constitutionality.

\section{BENEFICIOS FISCALES DECLARADOS INCONSTITUCIONALES Y LOS REFLEJOS ECONÓMICOS Y JURÍDICOS}

RESUMEN: En el artículo se tiene como objetivo estudiar los efectos jurídicos y económicos en la ocasión en que el Supremo Tribunal Federal declara un beneficio fiscal inconstitucional. Para la realización del estudio se empezó enunciando las ciencias que interfieren en el presente caso, el Derecho y la Economía. Se verificó que son ciencias independientes en sus méritos, pero con íntima relación, puesto su interdisciplinaridad. Se trató sobre la extra-fiscalidad de los tributos y su importancia en la economía. Se abordó el Derecho a Desarrollo y las características que deben nortear esa extra-fiscalidad. Además, se trató de los beneficios fiscales, como forma de incentivar la economía y los medios utilizados por los entes tributantes para exoneración tributaria. Presentó los efectos jurídicos y económicos de beneficios declarados inconstitucionales y enfatizando la posibilidad o no del fisco exigir el principal y multa de los contribuyentes que gozaron de esos beneficios considerados inconstitucionales. Para elaboración del artículo se utilizó el método deductivo con investigaciones bibliográficas.

PALABRAS CLAVE: Beneficio Fiscal; Derecho; Economía; Extra-fiscalidad; Inconstitucionalidad.

\section{INTRODUÇÃO}

O presente artigo tem como escopo estudar os benefícios fiscais declarados inconstitucionais e os reflexos econômicos e jurídicos.

Os benefícios fiscais são meios lícitos que podem e devem ser utilizados pelos entes tributantes, com o objetivo de fomentar a economia e, com isso, poder atingir um dos principais objetivos da República que é o Direito ao Desenvolvimento.

Obviamente que os entes tributantes não podem usar desses expedientes de qualquer forma, para não quebrar a livre concorrência e a neutralidade fiscal que 
deve nortear a estrutura fiscal nacional.

Ocorre que alguns benefícios fiscais são criados e não obedecem aos preceitos constitucionais e, tempos mais tarde, são considerados inconstitucionais. A partir disso, as empresas são compelidas a arcar com os ônus tributários desse benefício fiscal que aparentemente era legal, mas que foi considerado afronta à Constituição Federal.

Nesse contexto, a questão que se reflete é acerca dos efeitos jurídicos e econômicos dessa inconstitucionalidade declarada. Será que as empresas que usufruíram desses benefícios fiscais por vários anos poderão ser cobradas pelo fisco, se esse benefício for declarado inconstitucional?

Para a análise da temática proposta, apresenta-se inicialmente a relação entre a Economia e Direito que embasará uma discussão acerca dos reflexos econômicos e jurídicos dos benefícios fiscais. Neste mesmo sentido, analisa-se a extrafiscalidade do tributo e a importância dos benefícios fiscais para finalmente tecer considerações sobre o uso dos mesmos.

Para elaboração do artigo foi utilizado o método dedutivo com pesquisas bibliográficas.

\section{DIREITO E ECONOMIA: UMA INTER-RELAÇÃO NECESSÁRIA PARA A ANÁLISE DOS EFEITOS DA TRIBUTAÇÃO}

É cediço que Direito e Economia são ciências distintas, porém, há muitos anos há uma integração entre ambas.

A Economia dedica-se a satisfazer necessidades, administrando recursos escassos, ou seja, a atividade econômica é aquela aplicada na escolha de recursos para $\mathrm{o}$ atendimento destas necessidades humanas.

O fenômeno econômico, em muitas vezes, dita o surgimento de uma instituição jurídica ou vice-versa. Se ao Direito está dada a incumbência de organizar a ordem social, fazendo com que as pessoas possam viver em sociedade e se dentro da ordem social inclui-se também a Economia, é possível relacionar as relações entre Direito e Economia, para que haja uma sociedade mais igualitária, harmoniosa e em desenvolvimento.

Stigler apresenta um interessante conceito sobre Economia: 
Enquanto a eficiência constitui-se no problema fundamental dos economistas, a justiça é a preocupação que norteia os homens do direito [...] é profunda a diferença entre uma disciplina que procura explicar a vida econômica (e, de fato, todo o comportamento racional) e outra que pretende alcançar a justiça como elemento regulador de todos os aspectos da conduta humana. Esta diferença significa, basicamente, que o economista e o jurista vivem em mundos diferentes e falam diferentes línguas ${ }^{03}$.

Assim, por essas particularidades apontadas, há sem dúvida uma aproximação das duas ciências. Obviamente que isso gera conflito no meio acadêmico, uma vez que no meio jurídico muito veem com ressalva a aplicação de pensamentos não jurídicos como um objeto de pesquisa. Já no meio econômico há discussões acadêmicas no mesmo sentido. Não obstante, há um crescimento de estudos que analisam o Direito como sistêmico, analisando a sociedade em seu conjunto. ${ }^{04}$

Porém, o fato é que as ciências, pelas suas peculiaridades, demonstram inter-relação e cada vez mais uma interfere na outra, o que denota a importância de integrar cada vez mais essas questões.

Weber apud Heloísa Borges Esteves ${ }^{05}$ já havia notado que enquanto o estudo do Direito investiga o sentido dos preceitos que se apresentam como uma ordem determinante da conduta, estabelecendo-lhes o sentido lógico-formal e ordenando-os num em um sistema que, em princípio, não deve conter contradições, a Ciência Econômica diz respeito ao mundo dos acontecimentos reais, da distribuição de poder efetivo sobre recursos escassos e o modo pelo qual estes são empregados.

Bruno Meyerhof Salama sintetiza esta ideia da seguinte forma:

Enquanto o Direito é exclusivamente verbal, a Economia é também matemática; enquanto o Direito é marcadamente hermenêutico, a Economia é marcadamente empírica; enquanto o Direito aspira ser justo, a Economia aspira ser científica; enquanto a crítica econômica se dá pelo custo, a crítica jurídica se dá pela legalidade. Isso torna o diálogo entre economistas

\footnotetext{
${ }^{03}$ STIGLER, George. Law or Economics? The Journal of Law and Economics. October 1992, v. 35, n. $2,455-68$.

${ }^{04}$ LUHMANN, Niklas. O direito da sociedade. São Paulo: Martins Fontes, 2016.

${ }^{05}$ ESTEVES, Heloísa Borges. Economia e Direito são disciplinas que lidam com problemas de coordenação, estabilidade e eficiência na sociedade. Disponível em: < http://www.ie.ufrj.br/images/pos-graducao/ppge/Heloisa_Borges_Esteves.pdf > . Acesso em: 20 abr. 2018. p. 26.
} 
e juristas inevitavelmente turbulento, e geralmente bastante destrutivo ${ }^{06}$.

O Direito, entendido como um conjunto sistemático, ordenado, de regras que estruturam a vida do homem em sociedade, não se esgota apenas no estudo das normas jurídicas, englobando uma série de princípios e instituições capazes, no seu conjunto, de fornecer a caracterização da forma organizacional adotada por cada sociedade. Nesse sentido, o Direito pode ser estudado tanto em sua gênese histórica quanto a partir de sua enunciação atual e concreta ${ }^{07}$.

A formação do jurista tem grande influência das Leis, afastando quaisquer outras áreas, como se fosse uma ciência alheia às outras, como melhor dito, não se preocupando com questões não jurídicas.

Assim, a Teoria do Direito, nos termos expostos por Kelsen é essencialmente normativa.

A partir desta ideia, há dentro do Direito uma estrutura hierarquizada, cada norma deve encontrar seu fundamento em outra hierarquicamente superior, sendo a norma hipotética fundamental o fundamento para todo o ordenamento jurídico ${ }^{08}$.

Tratando especificamente da relação entre Direito e Economia, Miguel Reale ${ }^{09}$ afirma a existência de "[...] uma interação dialética entre o econômico e o jurídico, não sendo possível reduzir essa relação a nexos causais, nem tampouco a uma relação entre forma e conteúdo". Segundo o autor não haveria espaço, na ciência jurídica, para a investigação das relações causais comum na economia. Este tipo de posição, comum à pesquisa jurídica tradicional, acaba por "isolar" a pesquisa e o ensino do Direito (ao menos no Brasil), reduzindo as perspectivas de pesquisa interdisciplinar.

Por essas considerações, vislumbra-se que Direito e Economia são ciências com suas próprias características, mas que têm uma influência no outro e vice-versa, haja vista que os aspectos econômicos interferem nos jurídicos e os jurídicos interferem nos econômicos. Não tem como pensar em aprimoramento de direitos

\footnotetext{
${ }^{06}$ SALAMA, Bruno Meyerhof. O que é "Direito e Economia"? Uma introdução à epistemologia da disciplina para o Estudante, o Profissional e o Pesquisador em Direito". Disponível em: < http:// direitosp.fgv.br/publicacoes/direito-economia-introducao-epistemologia-disciplina-para-estudante-profissional-pesquis > . Disponível em: 20 abr. 2018.

${ }^{07}$ ESTEVES, Heloísa Borges. Economia e Direito são disciplinas que lidam com problemas de coordenação, estabilidade e eficiência na sociedade. Disponível em: < http://www.ie.ufrj.br/images/pos-graducao/ppge/Heloisa_Borges_Esteves.pdf > . Acesso em: 20 abr. 2018. p. 28.

${ }^{08}$ REALE, Miguel. Lições Preliminares de Direito. 25a ed. São Paulo: Saraiva, 2001. p. 20.

${ }^{09}$ Op. Cit., p. 21.
} 
fundamentais se não houver recursos financeiros. Assim, e principalmente para as discussões do direito tributário, Direito e Economia estão intimamente ligados. $\mathrm{Na}$ sequência analisa-se a extrafiscalidade do tributo para posteriormente discutir-se os benefícios fiscais

\section{A EXTRAFISCALIDADE DO TRIBUTO}

Conforme destacado anteriormente, um ponto muito importante para demonstração dessa relação entre o Direito e a Economia ocorre no que toca à parte tributária, em especial a função extrafiscal do tributo.

O tributo tem uma função precípua e destacada de arrecadação de recursos fundamentais para a realização das funções principais do Estado, lato sensu.

Contudo, essa função, atualmente, está aliada a outras atribuições, não menos importantes, dos tributos, tais como a redistribuição de renda, ocasião em que o Estado deve arrecadar os tributos e realizar políticas redistributivas, com o fim de diminuir a pobreza e as desigualdades naturais que existem no país das dimensões do Brasil.

Essa função fica fortalecida pelo Direito ao Desenvolvimento.

O Direito ao Desenvolvimento, segundo Samyra H. Dal Farra Naspolini e Vladmir Oliveira da Silveira, seria

[...] um direito humano cujas dimensões são variadas e de prática progressiva, uma vez que se efetiva por meio da revitalização e realização dos direitos já existentes. Revela-se como um direito humano integrador, ou seja, a sua efetivação está diretamente ligada à concretização conjunta dos direitos civis e políticos e dos direitos econômicos, sociais e culturais ${ }^{10}$.

A Constituição Federal de 1988 referencia o desenvolvimento no próprio preâmbulo ao enunciar que o Estado democrático brasileiro, que se institui a partir desta Carta, está compromissado, dentre outros fins, a assegurar o desenvolvimento da sociedade brasileira.

Já o artigo $1^{\mathrm{o}}$ da Constituição Federal, em seu inciso III, dispõe que a digni-

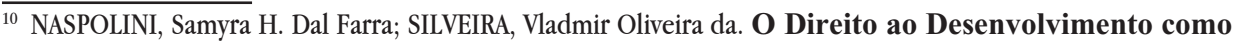
Direito Humano Fundamental de Terceira Dimensão. Disponível em: < https://periodicos.unipe. br/index.php/direitoedesenvolvimento/article/viewFile/608/346 > . Acesso em: 02 nov. 2017. 
dade da pessoa humana é um dos fundamentos da República Federativa do Brasil, enquanto o artigo 170 a coloca como fundamento da ordem econômica brasileira ${ }^{11}$. Veja o dispositivo da Constituição Federal:

Art. $3^{\circ}$ Constituem objetivos fundamentais da República Federativa do Brasil:

I - construir uma sociedade livre, justa e solidária;

II - garantir o desenvolvimento nacional;

III - erradicar a pobreza e a marginalização e reduzir as desigualdades sociais e regionais;

IV - promover o bem de todos, sem preconceitos de origem, raça, sexo, cor, idade e quaisquer outras formas de discriminação.

$\mathrm{O}$ artigo $3^{\circ}$ da Carta Constitucional, por sua vez, não determina quais os contornos do desenvolvimento almejado pelo constituinte originário, ou ainda, quais os instrumentos para efetivá-lo e nem como os cidadãos podem exigir-lhe o cumprimento.

De certa forma, para o desenvolvimento econômico nacional neste contexto de globalização deve ser salientada a redução dos gastos públicos, com um processo de diminuição da carga tributária, capaz de permitir uma maior disponibilidade de recursos para a poupança, investimento ou consumo.

Esse exemplo de auxílio da tributação para o desenvolvimento econômico decorre da extrafiscalidade, que é vista como um incentivo ao uso de instrumentos tributários visando a atingir finalidades não arrecadatórias. É um implemento na concessão de isenções, simplesmente objetivando recomendar ao cidadão uma ação ou omissão.

Além disso, o tributo tem como objetivo a interferência na Economia, criando mecanismos de indução ou a não estimulação sobre consumo ou aquisição de produtos e/ou serviços. Essa é a função extrafiscal dos tributos.

Isso, pois, sempre que há alguma modificação na política fiscal, seja no âmbito do Município, do Estado, ou da União, alguma consequência econômica tam-

\footnotetext{
${ }^{11}$ RIBEIRO, Maria de Fátima; FERRER, Wakiria Martinez Heinrich. Os incentivos fiscais e os impactos da função socioeconômica dos tributos para o desenvolvimento sustentável. Disponível em: $<$ https: $/ /$ www.google.com.br/url?sa $=t \& r c t=j \& q=\&$ esrc $=s \&$ source $=$ web\&cd $=2 \& v e d=0$ ahUKEwi $4 x u-$ PB9LfQAhWMhpAKHeJmCfoQFggkMAE\&url=http\%3A\%2F\%2Ffacnopar.com.br\%2Frevista\%2Farquivos\%2F13\%2F10_ribeiro_e_gesteiro_a_busca_da_cidadania_fical\%5B1\%5D.pdf\&usg=AFQjCNFVKfjMjEVTlp3ooSDC6RiL 9 FuqeQ $\overline{\mathrm{Q}}>$. Acesso em: 20 nov. $20 \overline{1} 7$.
} 
bém ocorrerá.

Porém, os efeitos poderão ser benéficos ou prejudiciais, o que denota que esse tema é mais relevante para a Economia do que para o Direito.

É certo que há algumas situações em que o Direito intervém na parte tributária, utilizando-se da extrafiscalidade, mas que essa situação não gera diretamente reflexos na Economia, mas tem apenas o fim de adequar os comportamentos sociais. Exemplo evidente disso, como assevera Paulo Caliendo, "está na progressividade extrafiscal do IPTU progressivo como instrumento de política urbana, previsto no art. $182, \S 4^{\circ}$, inc. II da CF/88”"12.

Ainda segundo o autor, neste desiderato, o imposto tem por escopo punir um mau uso da propriedade urbana, mediante não utilização, subutilização ou não edificação, conforme a política urbana.

Contudo, na maioria dos casos, a função extrafiscal interfere na Economia.

Através da política extrafiscal, o legislador fiscal poderá estimular ou desestimular comportamentos, de acordo com os interesses da sociedade, por meio de uma tributação regressiva ou progressiva, ou quanto à concessão de incentivos fiscais.

A extrafiscalidade tem papel fundamental para a correção de situações econômicas e sociais anômalas e atuar em prol do meio ambiente e na diminuição de desigualdades sociais.

Em regra, a tributação deve ser uniformidade em todo território nacional. Porém, em busca do desenvolvimento nacional e pela extrafiscalidade, cabe ao Estado criar meios de tributação especial para regiões menos desenvolvidas, para que, com isso, haja uma integração nacional mais efetiva.

Verificou-se que um exemplo dessa tributação especial para fomentar a integração social é a Zona Franca de Manaus, que atraiu para aquela área amazônica não só o desenvolvimento do comércio, como da indústria e agropecuária, com destaque especial para o ramo eletrônico avançado, que se beneficiam das facilidades de importação de peças e componentes de aparelhos eletroeletrônicos.

Assim, o Estado poderá se utilizar de algumas técnicas para implementação

${ }_{12}$ CALIENDO, Paulo. Tributação e ordem econômica: os tributos podem ser utilizados como instrumentos de indução econômica? Disponível em: <http://revistaeletronicardfd.unibrasil.com.br/ index.php/rdfd/article/view/685/471 > . Acesso em: 10 maio 2018. p. 197. 
dessa funçãa ${ }^{13}$ : a utilização de alíquota progressiva, seletivas, isenções fiscais ${ }^{14}$, reduções de alíquotas, aproveitamento de créditos fiscais, depreciação acelerada, dentre tantos outros ${ }^{15}$. O instrumento técnico permitirá a indução de determinados comportamentos tornando a carga fiscal menor ou desincentivando, tornando-a mais gravosa, conforme elucida Paulo Caliendo ${ }^{16}$.

Um ponto que é interessante focar é que, com base nas lições de Paulo Caliendo, há tributos com finalidades extrafiscais e os efeitos extrafiscais dos tributos. Ambas são temáticas distintas. É cediço que todo tributo tem efeitos fiscais e extrafiscais. Assim, a Economia é atingida diretamente por esses aspectos.

Todavia, alerta Paulo Caliendo que:

Tal entendimento não significa abdicar da autonomia do Direito Tributário perante a economia ou a ciência das finanças, pelo contrário seria uma forma de fortalecer o papel prescritivo do Direito sobre a realidade social. As normas jurídicas deixam de serem entendidas como objetos ideais e passam a serem compreendidas como comandos pragmáticos-normati$\operatorname{vos}^{17}$.

Em contrapartida, existem tributos que têm sua essência finalidade extrafiscal claramente definida no ordenamento jurídico, haja vista que incorporam tais características como parte de sua estrutura normativa. O IOF, o IPI, o II e o IE são exemplos típicos desses impostos com finalidade extrafiscal, tendo em vista que possuem como finalidade relevante a de regular determinado setor econômico (mercado financeiro, industrial ou comércio exterior) ${ }^{18}$.

${ }^{13}$ Artigo $2^{\circ}$ do Estatuto dos Benefícios Fiscais de Portugal: "2 - São benefícios fiscais as isenções, as reduções de taxas, as deduções à matéria colectável e à colecta, as amortizações e reintegrações aceleradas e outras medidas fiscais que obedeçam às características enunciadas no número anterior".

${ }^{14}$ Sobre a natureza das isenções veja-se COÊLHO, Sacha Calmon Navarro. Teoria Geral do Tributo, da Interpretação e da Exoneração Tributária (O significado do art. 116, parágrafo único, do CTN). São Paulo: Dialética, 2003, p. 218-219.

15 TÔRRES, Heleno Taveira. Desenvolvimento, meio ambiente e extrafiscalidade no Brasil. In: Pires, Manuel. Extrafiscalidade. Lisboa: Universidade Lusíada, 2011, p. 85-115.

${ }^{16}$ CALIENDO, Paulo. Tributação e ordem econômica: os tributos podem ser utilizados como instrumentos de indução econômica? Disponível em: <http://revistaeletronicardfd.unibrasil.com.br/index.php/rdfd/ article/view/685/471 >. Acesso em: 10 maio 2018. p. 199.

${ }^{17}$ CALIENDO, Paulo. Tributação e ordem econômica: os tributos podem ser utilizados como instrumentos de indução econômica? Disponível em: <http://revistaeletronicardfd.unibrasil.com.br/index.php/rdfd/ article/view/685/471>. Acesso em: 10 maio 2018. p. 200.

${ }^{18}$ CALIENDO, Paulo. Tributação e ordem econômica: os tributos podem ser utilizados como instrumentos de indução econômica? Disponível em: <http://revistaeletronicardfd.unibrasil.com.br/index.php/rdfd/ article/view/685/471>. Acesso em: 10 maio 2018. p. 200. 
Tanto é fato essa característica que não se aplicam os princípios da legalidade, anterioridade e da periodicidade mínima.

Assim, a extrafiscalidade se manifesta de diversas formas dentro do sistema constitucional nacional, especialmente pela criação de benefícios fiscais, temática que será analisada na sequência.

\section{OS BENEFÍCIOS FISCAIS}

Vige no modelo constitucional a regra da não intervenção do Estado nas relações particulares, uma vez que vale a livre iniciativa, nos termos do artigo 170, caput, da Constituição Federal.

Além do que, no aspecto tributário, existe a previsão constitucional da neutralidade da tributação, ou seja, a tributação deve ser neutra e evitar tratamento distinto entre as pessoas e empresas.

Como observa Luís Roberto Barroso ${ }^{19}$, neutralidade é um conceito complexo, que se dilui em muitos aspectos diferentes. Alguns deles, segundo o ilustre professor, são: i) a imparcialidade, que representa a ausência de interesse imediato nas questões; e ii) a impessoalidade, que corresponde à atuação pelo bem comum, e não para o favorecimento de alguém. E continua Barroso:

A ideia [sic] de neutralidade do Estado, das leis e de seus intérpretes, divulgada pela doutrina liberal-normativista, toma por base o status quo. Neutra é a decisão ou a atitude que não afeta nem subverte as distribuições de poder e riqueza existentes na sociedade, relativamente à propriedade, renda, acesso às informações, à educação, às oportunidades etc. Ora bem: tais distribuições, isto é, o status quo - não são fruto do frequentemente, nada têm de justas. A ordem social vigente é fruto de fatalidades, disfunções e mesmo perversidades históricas. Usá-la como referência do que seja neutro é evidentemente indesejável, porque instrumento de perenização da injustiça. Veja-se que o problema não está só na neutralidade em si, mas em qual ponto de referência do que seja neutro. O status quo vigente nas sociedades desiguais - e poucas não o são - certamente não pode fundar-se no status quo não significa que não haja lugar para ela. Idealmente, o intérprete, o aplicador do

19 BARROSO, Luís Roberto. Interpretação e Aplicação da Constituição. São Paulo: Saraiva, 1996. p. 288-289. 


$$
\text { direito, o juiz, deve ser neutro }{ }^{20} \text {. }
$$

Nestes termos, o uso de isenções e benefícios fiscais é uma medida excepcional, nos termos do que expõe Paulo Caliendo. Arremata aduzindo que:

A sua utilização deve ser complementar e coerente com o sistema geral, não podendo servir para criar novas iniquidades, complexidade desnecessária no sistema ou desorganizar o sistema econômico por isenções distorcivas do mercado. A proteção do mercado é uma questão de ordem pública em nosso sistema ${ }^{21}$.

É assim que se revela, no aspecto constitucional, uma finalidade para a ordem econômica, uma vez que prestigiada a atividade individual (livre iniciativa e trabalho humano), enquanto meio para atingir os objetivos fundamentais da República.

Segundo André Elali, no texto "Incentivos fiscais, neutralidade da tributação e desenvolvimento econômico: a questão da redução das desigualdades regionais e sociais", assevera que as normas tributárias indutoras, para o fim de interferir na ordem econômica, a partir do modelo previsto na Constituição Federal, instituem benefícios e/ou agravamentos, visando à realização de comportamentos mais desejáveis pelos agentes econômicos ${ }^{22}$.

Assim, os incentivos fiscais são os instrumentos aplicáveis para servirem à indução econômica nas hipóteses de benefícios que passam a ser outorgados para incentivar comportamentos específicos.

Há as seguintes formas de incentivos fiscais: i) as subvenções, que constituem um benefício de natureza financeira ${ }^{23}$. $\mathrm{O}$ autor considera as subvenções um instituto próprio do direito financeiro, por se tratarem de ajudas pecuniárias, concedidas pelo Estado em favor de instituições que prestam serviços e/ou realizam obras

${ }^{20}$ BARROSO, Luís Roberto. Interpretação e Aplicação da Constituição. São Paulo: Saraiva, 1996. p. 288-289, p. 288-289.

${ }^{21}$ CALIENDO, Paulo. Tributação e ordem econômica: os tributos podem ser utilizados como instrumentos de indução econômica? Disponível em: <http://revistaeletronicardfd.unibrasil.com.br/index.php/rdfd/ article/view/685/471>. Acesso em: 10 maio 2018. p. 209.

${ }^{22}$ ELALI, André. Incentivos fiscais, neutralidade da tributação e desenvolvimento econômico: a questão da redução das desigualdades regionais e sociais. Disponível em: <http://sisnet.aduaneiras.com.br/ lex/doutrinas/arquivos/070807.pdf > . Acesso em: 10 maio 2018.

${ }^{23}$ CARvalHOSA, Modesto. Comentários à Lei de Sociedades Anônimas. São Paulo: Saraiva, 1997, v. 3, p. 603 
do interesse público; ii) os créditos presumidos, que têm natureza complexa, ora apresentando-se como subsídio, ora como subvenção, ora como mera redução da base de cálculo dos tributos ${ }^{24}$; iii) os subsídios, que podem ser estímulos de natureza fiscal ou comercial, para promover determinadas atividades econômicas por períodos transitórios. Ricardo Lobo Torres entende que os subsídios podem ser incluídos no conceito mais abrangente de subvenção 25 .

Para Adilson Rodrigues Pires, subsídio é toda ajuda oficial do governo com o fim de estimular a produtividade de indústrias, tendo como objetivo promover o desenvolvimento de setores estratégicos sob o ponto de vista econômico, ou de regiões mais atrasadas, "além de servir como instrumento de incentivo às exportações, sobretudo em países em desenvolvimento"26. E Marcos André Vinhas Catão encara-os como:

[...] incentivos fiscais destinados a promover determinada atividade econômica, com o fim de equalizar preços e permitir, durante período transitório, o estímulo ou até mesmo a proteção de um setor produtivo. Tem íntima relação, portanto, com a formação de preço de venda de determinada mercadoria ou bem. $^{27}$

Ademais: iv) as isenções tributárias, que evitam o nascimento, por lei, da própria obrigação tributária ${ }^{28}$; e v) o diferimento, que representa uma isenção condicionada, na linguagem usada, dentre outros, por Roque Antonio Carrazza ${ }^{29}$.

O papel promocional dos incentivos fiscais consiste no servir como medida para impulsionar ações ou corretivos de distorções do sistema econômico, visando a atingir certos benefícios, cujo alcance poderia ser tanto ou mais dispendioso, em vista de planejamentos públicos previamente motivados $^{30}$.

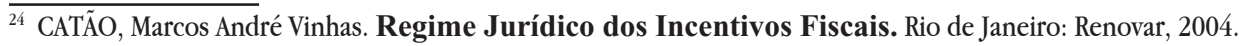
p. 71.

${ }_{25}$ TORRES, Ricardo Lobo. Os Direitos Humanos e a Tributação. Rio de Janeiro: Renovar, 1995. p. 296.

${ }^{26}$ PIRES, Adilson Rodrigues Pires. Práticas Abusivas no Comércio Internacional. Rio de Janeiro: Forense, 2001. p. 201.

${ }^{27}$ CATÃO, Marcos André Vinhas. Regime Jurídico dos Incentivos Fiscais. Rio de Janeiro: Renovar, 2004. p. 73.

${ }^{28}$ ELALI, André. Incentivos fiscais, neutralidade da tributação e desenvolvimento econômico: a questão da redução das desigualdades regionais e sociais. Disponível em: < http://sisnet.aduaneiras.com.br/ lex/doutrinas/arquivos/070807.pdf > . Acesso em: 10 maio 2018.

${ }^{29}$ CARRAZZA, Roque Antonio. ICMS. São Paulo: Malheiros, 2000. p. 218.

${ }^{30}$ TÔRRES, Heleno Taveira. Incentivos Fiscais na Constituição e o "Crédito-prêmio de IPI". In: Direito Tributário Atual - 18. São Paulo: Dialética \& Instituto Brasileiro de Direito Tributário, 2005. p. 79. 
Assim, um benefício fiscal efetivo deve sempre buscar atingir um aspecto econômico, para fomentar a economia de alguma forma e conseguir atingir o desenvolvimento econômico almejado pela República Federativa do Brasil.

Desta feita, quando concedido um benefício fiscal, cabe ao ente tributante concessor fazer uma análise meticulosa da estrutura econômica para ver a sua real necessidade, bem como se esse benefício está ou não quebrando a livre iniciativa, ou seja, a não intervenção do Estado, via de regra, bem como se não prejudica a neutralidade da tributação.

\section{BENEFÍCIOS FISCAIS DECLARADOS INCONSTITUCIONAIS E OS EFEITOS JURÍDICOS E ECONÔMICOS}

É sabido que o Poder Judiciário é guardião da Constituição Federal e da legislação, sendo que o artigo $5^{\circ}, \mathrm{XXV}$, consagra o princípio da inafastabilidade da jurisdição, uma vez que lesão ou ameaça de lesão a direito devem ser resguardados pelo Estado-juiz, haja vista que se veda o exercício da justiça com as próprias mãos.

Segundo esclarecimentos de Alexandre de Moraes:

O Poder Judiciário, desde que haja plausibilidade de ameaça ao direito, é obrigado a efetivar o pedido de prestação judicial requerido pela parte de forma regular, pois a indeclinabilidade da prestação judicial é princípio básico que rege a jurisdição, uma vez que a toda violação de um direito responde uma ação correlativa, independentemente de lei especial que a outorgue $^{31}$.

Quando o art. $5^{\circ}, \mathrm{XXXV}$, declara que a lei não excluirá da apreciação do Poder Judiciário lesão ou ameaça a direito, vem possibilitar o ingresso em juízo para assegurar direitos simplesmente ameaçados. Assim, a Constituição amplia o direito de acesso ao Judiciário, antes da concretização da lesão.

Uma dessas atribuições do Poder Judiciário é a análise e controle desses benefícios fiscais, especialmente quanto à sua constitucionalidade, descumprimento aos princípios constitucionais, entre outros aspectos, comum às discussões judiciais

\footnotetext{
${ }^{31}$ MORAES, Alexandre de. Direitos Humanos Fundamentais. Teoria Geral. Comentários aos arts. $1^{\circ}$ a $5^{\circ}$ da Constituição da República Federativa do Brasil. Doutrina e Jurisprudência. $2^{\mathrm{a}}$ ed. São Paulo: Atlas, 1998. p. 197.
} 
sobre violação ao princípio da isonomia tributária ou então com relação aos limites de determinada regra de isenção.

Porém, essas altercações não ficam adstritas aos particulares em face dos entes tributantes, com questões como as acima indicadas. Os conflitos no Judiciário envolvendo os benefícios fiscais vão muito mais além, haja vista que de uns anos para cá, tem aumentado sensivelmente os casos de guerra fiscal entre Municípios, Estados e, também, entre Nações.

Todas essas divergências judiciais decorrem da busca desenfreada dos entes tributantes por mais empresas em seus territórios, atribuindo diminuição ou erradicação da carga tributária, mesmo que tal mecanismo seja feito ao arrepio da Constituição Federal.

Exemplo bastante corriqueiro acontece com os tributos como o Imposto sobre Serviços (ISS-QN), Imposto sobre circulação de mercadorias e serviços de transporte interestadual, intermunicipal e de comunicação (ICMS).

Os Municípios e os Estados, respectivos entes competentes para os impostos indicados, criam programas para atrair novas empresas, passando por cima de regras constitucionais, na maior parte das vezes.

No que toca aos benefícios fiscais, que são vetores da guerra fiscal do ISS-QN entre os Municípios, decorre principalmente pela utilização de alíquotas abaixo do que é determinado pelo Ato das Disposições Constitucionais Transitórias. A ADCT determina que o ISS-QN deva ser no mínimo de $2 \%$ (dois por cento). Todavia, alguns municípios criam programas para atrair novas empresas e oferecem ISS-QN abaixo desse mínimo ou muitas vezes em zero por cento.

Já relacionadas aos incentivos fiscais de ICMS concedidos por algum Estado há que se obedecer as regras previstas nos artigos $155, \S 2^{\circ}$, XII, "g", da Constituição Federal $^{32}$ e $2^{\circ}$, $\S 2^{\circ}$, da Lei Complementar 24 de $1975^{33}$. Os citados preceitos determinam que para um Estado poder aprovar um benefício fiscal deverá levar a sua

\footnotetext{
$\overline{32}$ Art. 155. Compete aos Estados e ao Distrito Federal instituir impostos sobre:

[...]

XII - cabe à lei complementar:

g) regular a forma como, mediante deliberação dos Estados e do Distrito Federal, isenções, incentivos e benefícios fiscais serão concedidos e revogados.

${ }^{33}$ Art. $2^{\circ}$ - Os convênios a que alude $o$ art. $1^{\circ}$, serão celebrados em reuniões para as quais tenham sido convocados representantes de todos os Estados e do Distrito Federal, sob a presidência de representantes do Governo federal.

$\S 2^{\circ}$ - A concessão de benefícios dependerá sempre de decisão unânime dos Estados representados; a sua revogação total ou parcial dependerá de aprovação de quatro quintos, pelo menos, dos representantes presentes.
} 
submissão ao Conselho Nacional de Política Fazendária (Confaz).

Em contrapartida, muitos Estados acabam criando programas de benefícios fiscais com o ICMS de forma unilateral, sem a aprovação do Confaz, o que gera um desequilíbrio no pacto federativo e afronta a previsão constitucional. Nem se diga sobre a correção dessa necessidade de ter unanimidade para aprovação do benefício no Confaz, mas o fato é que o Estado que faz isso, fomenta a guerra fiscal e incrementa a briga entre os outros Estados.

Nas duas situações acima apontadas, apenas a título exemplificativo, fazem com que o ente que se sentir prejudicado possa socorrer-se do Poder Judiciário para discutir judicialmente os referidos benefícios fiscais concedidos indevidamente. Exemplo disso são as ADIs 2.663 e 3.796 que estão para serem apreciadas pelo Supremo Tribunal Federal.

O grande impasse disso, além dessas disputas judiciais, é que várias empresas utilizam-se desses benefícios fiscais inconstitucionais, às vezes por vários anos, diante da demora do Poder Judiciário em decidir as ações. As empresas que aderem a esses benefícios fiscais normalmente fazem de boa-fé e mudam para esses municípios e/ou Estados com o objetivo de diminuir a carga tributária, fazendo grandes investimentos e mudanças para se adequarem às regras dos programas.

Nestes termos, a questão que fica é: essas empresas de boa-fé e protegidas por esses benefícios fiscais, que são declarados inconstitucionais pelo Poder Judiciário, em decorrência da guerra fiscal, podem ser cobradas pelos tributos que não pagaram na vigência do benefício irregular e de forma retroativa?

Essa simples questão gera sérias discussões judiciais e doutrinárias, uma vez que não há, por ora, um consenso no Supremo Tribunal Federal.

Todavia, salvo melhor juízo, a resposta desta questão, com base em critérios econômicos e jurídicos deve ser não, uma vez que a empresa de boa-fé não pode ser prejudicada por uma medida que ela não deu causa. Isso decorre do princípio da segurança jurídica.

A segurança jurídica que se garante aos cidadãos a previsibilidade dos efeitos jurídicos de suas condutas e, ao mesmo tempo, a certeza da coisa julgada e dos direitos adquiridos. Não há que se falar em certeza do direito, mas sim na previsibilidade dos atos futuros e na garantia dos atos passados.

Neste sentido, vale aqui citar Paulo de Barros Carvalho: 
Não há por que confundir a certeza do direito naquela acepção de índole sintática, com o cânone da segurança jurídica. Aquele é atributo essencial, sem o que não se produz enunciado com sentido deôntico; este último é decorrência de fatores sistêmicos que utilizam o primeiro de modo racional e objetivo, mas dirigido à implantação de um valor específico, qual seja o de coordenar o fluxo das interações inter-humanas, no sentido de propagar no seio da comunidade social o sentimento de previsibilidade quanto aos efeitos jurídicos da regulação da conduta. Tal sentimento tranquiliza os cidadãos, abrindo espaço para o planejamento de ações futuras, cuja disciplina jurídica conhecem, confiantes que estão no modo pela qual a aplicação das normas do direito se realiza. Concomitantemente, a certeza do tratamento normativo dos fatos já consumados, dos direitos adquiridos e da força da coisa julgada, lhes dá a garantia do passado ${ }^{34}$.

O princípio em destaque também tem importância quanto ao tema, pois é esperada do fisco uma conduta que conceda ao contribuinte uma segurança jurídica nas relações.

Para Paulo Caliendo:

O princípio da segurança jurídica exige a vedação à incidência de tributos a fatos que firam as expectativas legítimas dos contribuintes, sua boa-fé ou a estabilidade das relações jurídicas. Um dos exemplos está na vedação de tributos retroativos, ou seja, a fatos geradores anteriores ao início da vigência da lei que os houver instituído ou aumentado (art. 150, inc. III, a, da CF). A proteção dos fatos geradores anteriores à cobrança de tributos é um dos direitos fundamentais do contribuinte mais importantes, visto que preserva a sua segurança, seus direitos e a sua propriedade ${ }^{35}$.

Ademais, Paulo Caliendo complementa dizendo que no caso em apreço há flagrante violação ao princípio da confiança legítima.

O princípio da confiança legítima pode ser visto como ampliação do princípio da segurança jurídica ou como um novo princípio autônomo. Independente de que posição se adote, importa explicar sua origem e extensão.

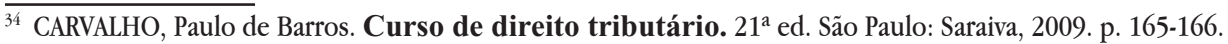

${ }^{35}$ CALIENDO, Paulo. Tributação e ordem econômica: os tributos podem ser utilizados como instrumentos de indução econômica? Disponível em: < http://revistaeletronicardfd.unibrasil.com.br/index.php/rdfd/ article/view/685/471>. Acesso em: 10 maio 2018. p. 217. 
O princípio da confiança tem como leading case situação ocorrida na Alemanha, na década de 50, do século passado. Depois de reconhecido nos tribunais passou a ser tratado na doutrina para, só então, ser positivado. A Espanha também cuidou deste princípio de forma pioneira. Hoje em toda a Europa há ampla aceitação do seu uso.

A ideia de confiança legítima defende a manutenção de atos administrativos, cujos efeitos se prolongaram no tempo, gerando no administrado uma expectativa legítima de continuidade, ainda que estes atos sejam eivados de ilegalidade ou inconstitucionalidade. A proteção da confiança tem por pano de fundo a necessidade de estabilização das relações ente a administração pública e os administrados ${ }^{36}$.

Os princípios já mencionados denotam que o fisco deve ter cautela ao conceder benefícios fiscais ao arrepio da Constituição, uma vez que prejudicam os outros entes da federação, bem como pode lesar outras empresas que de boa-fé usufruem desses benefícios e depois são acionadas a devolver valores que se beneficiaram.

Ademais, não pode perder de vista que isso fere também a livre concorrência, haja vista que uma empresa com benefício fiscal pode vender seus produtos e/ ou serviços com um custo menor do que os concorrentes que eventualmente não detenham do mesmo benefício. Assim, causa um desequilíbrio no mercado concorrencial de forma indevida. Por isso, os governantes devem ter parcimônia ao realizar um programa de incentivo fiscal, fazendo com que este benefício traga desenvolvimento econômico para o município, Estado e União.

Além desses aspectos jurídicos que sofrem interferência em decorrência de benefícios fiscais declarados inconstitucionais, há os aspectos econômicos, haja vista que a empresa quando se utilizou do benefício fiscal concedido precificou seus produtos ou serviços com base nessa carga tributária já encampando esses benefícios. Se alguns anos depois esse benefício for considerado inconstitucional e o fisco exigir a restituição do valor seria economicamente incorreto, uma vez que o valor não foi repassado ao consumidor final e, com isso, a empresa não aumentou sua margem de lucro.

Por isso, a empresa utilizou-se do benefício fiscal e conseguiu vender seu produto ou serviço com menor preço e depois se for compelido a ressarcir esse tributo terá que tirar do seu capital, o que pode gerar uma dificuldade financeira para

\footnotetext{
${ }^{36}$ ROCHA, Ludiana Carla Braga Façanha; DINIZ, Márcio Augusto de Vasconcelos. A administração púbica e o princípio da confiança legítima. Disponível em: < http://www.egov.ufsc.br/portal/sites/default/files/ anexos/32601-39843-1-PB.pdf>. Acesso em: 09 maio 2018.
} 
a empresa, inclusive com demissões, atraso no pagamento de fornecedores, entre consequências mais graves, como a quebra da empresa.

Desta feita, um benefício fiscal declarado inconstitucional faz repercutir aspectos jurídicos e econômicos, o que denota a importância de os entes realizarem benefícios fiscais em obediência aos preceitos constitucionais e legais, em busca de um benefício fiscal que atinja os objetivos da República Federativa do Brasil, mantenha o equilíbrio do Pacto Federativo e traga condições vantajosas paras as empresas.

\section{CONSIDERAÇÕES FINAIS}

A Economia tem o escopo de verificar a melhor escolha dos recursos para o atendimento das necessidades humanas.

Já o Direito é o conjunto de regras que estruturam a vida do homem em sociedade, preocupando-se com a análise de princípios, com a finalidade de conceder mecanismos organizacionais para cada sociedade.

São duas ciências distintas, mas que possuem relação de interdependência, ante o fato de que os aspectos jurídicos interferem nos econômicos e vice-versa.

No segundo tópico foi analisada a extrafiscalidade dos tributos. Viu-se que a principal atribuição do tributo é angariar recursos para o ente tributante realizar suas principais funções ordinárias. Porém, em complemente a essa função há a de servir para redistribuir a riqueza do país e a função extrafiscal que tem por escopo fomentar o Direito ao Desenvolvimento, que é um dos objetivos da República.

Assim, a função extrafiscal tem como objetivo a interferência na Economia, criando mecanismos de indução ou a não estimulação sobre consumo ou aquisição de produtos e/ou serviços.

Uma das formas de aplicação dessa extrafiscalidade é a concessão de benefícios fiscais. É cediço que a Constituição Federal adotou a livre iniciativa e, por isso, deve o ente tributante ter zelo ao instituir desonerações tributárias, sob pena de violar esse princípio basilar.

O papel dos incentivos fiscais consiste como meio de impulsionar ações ou corretivos de distorções do sistema econômico.

No último tópico foram expostos os aspectos jurídicos e econômicos dos benefícios fiscais declarados inconstitucionais, em especial os decorrentes de guer- 
ras fiscais, ocasião em que os entes tributantes criam mecanismos para atrair novas empresas para seus domínios e, muitas das vezes, benefícios concedidos em desacordo com a Constituição Federal.

Diante disso, se tempos depois o Supremo Tribunal Federal declarar aquele benefício fiscal inconstitucional, diversas consequências podem ser elucidadas, no aspecto jurídico e/ou econômico.

Isso, pois, muitas das vezes as empresas que gozaram desses benefícios agiram de boa-fé e, depois de vários anos, podem ser compelidas a ter que devolver, acrescido de juros, multas e com isso gerar um desequilíbrio na saúde financeira da empresa.

Em atenção ao princípio da segurança jurídica as condutas do Estado (lato sensu) devem primar pela previsibilidade dos seus atos, para que o contribuinte não seja surpreendido por medidas desarrazoadas.

Além do mais, espera-se uma confiança da Administração Pública, para vedar que aquele que agiu de boa-fé seja prejudicado por uma conduta inesperada.

Mas as intercorrências advindas desse fato não ficam adstritas apenas aos aspectos jurídicos e respingam na Economia, já que quando da concessão do benefício a empresa beneficiada conseguiu diminuir o custo do seu produto ou serviço e, normalmente, gera uma diminuição, em corolário do benefício fiscal, do preço ao consumidor final. Se tempo depois vier a ser cobrado por esses tributos que deixou de pagar, em decorrência do benefício fiscal, a empresa terá que tirar do seu faturamento, o que gerará um desfalque considerável na empresa.

Por esse motivo, cabe aos entes tributantes terem parcimônia para utilizarem dos benefícios fiscais, evitando o seu uso indiscriminado e sem observar a Constituição Federal, sob pena de vilipendiar o Pacto Federativo e o direito das empresas que se usufruíram desses benefícios fiscais, uma vez que acarretará em lesão jurídica e econômica.

\section{REFERÊNCIAS}

BARROSO, Luís Roberto. Interpretação e Aplicação da Constituição. São Paulo: Saraiva, 1996.

CALIENDO, Paulo. Tributação e ordem econômica: os tributos podem ser utiliza- 
dos como instrumentos de indução econômica? Disponível em: < http://revistaeletronicardfd.unibrasil.com.br/index.php/rdfd/article/view/685/471>. Acesso em: 10 maio 2018.

CARRAZZA, Roque Antonio. ICMS. São Paulo: Malheiros, 2000.

CARVALHO, Paulo de Barros. Curso de direito tributário. 21. ed. São Paulo: Saraiva, 2009.

CARVALHOSA, Modesto. Comentários à Lei de Sociedades Anônimas. São Paulo: Saraiva, 1997. v. 3.

CATÃO, Marcos André Vinhas. Regime Jurídico dos Incentivos Fiscais. Rio de Janeiro: Renovar, 2004.

COÊLHO, Sacha Calmon Navarro. Teoria Geral do Tributo, da Interpretação e da Exoneração Tributária (O significado do art. 116, parágrafo único, do CTN). São Paulo: Dialética, 2003.

ELALI, André. Incentivos fiscais, neutralidade da tributação e desenvolvimento econômico: a questão da redução das desigualdades regionais e sociais. Disponível em: < http://sisnet.aduaneiras.com.br/lex/doutrinas/arquivos/070807.pdf> . Acesso em: 10 maio 2018.

ESTEVES, Heloísa Borges. Economia e Direito são disciplinas que lidam com problemas de coordenação, estabilidade e eficiência na sociedade. Disponível em: < http://www.ie.ufrj.br/images/pos-graducao/ppge/Heloisa_Borges_Esteves. pdf $>$. Acesso em: 20 abr. 2018.

LUHMANN, Niklas. O direito da sociedade. São Paulo: Martins Fontes, 2016.

MORAES, Alexandre de. Direitos Humanos Fundamentais. Teoria Geral. Comentários aos arts. $1^{\circ}$ a $5^{\circ}$ da Constituição da República Federativa do Brasil. Doutrina e Jurisprudência. 2. ed. São Paulo: Atlas, 1998.

NASPOLINI, Samyra H. Dal Farra; SILVEIRA, Vladmir Oliveira da. O Direito ao Desenvolvimento como Direito Humano Fundamental de Terceira Dimensão. 
Disponível em: < https://periodicos.unipe.br/index.php/direitoedesenvolvimento/ article/viewFile/608/346>. Acesso em: 02 nov. 2017.

PIRES, Adilson Rodrigues Pires. Práticas Abusivas no Comércio Internacional. Rio de Janeiro: Forense, 2001.

REALE, Miguel. Lições Preliminares de Direito. 25. ed. São Paulo: Saraiva, 2001.

RIBEIRO, Maria de Fátima; FERRER, Wakiria Martinez Heinrich. Os incentivos fiscais e os impactos da função socioeconômica dos tributos para o desenvolvimento sustentável. Disponível em: <https://www.google.com.br/ url $? \mathrm{sa}=\mathrm{t} \& \mathrm{rct}=\mathrm{j} \& \mathrm{q}=\& \mathrm{esrc}=\mathrm{s} \&$ source $=$ web\&cd $=2 \& \mathrm{ved}=0$ ahUKEwi4xuPB9LfQAhWMhpAKHeJmCfoQFggkMAE\&url = http\%3A\%2F\%2Ffacnopar.com.br\%2Frevista\%2Farquivos\%2F13\%2F10_ribeiro_e_gesteiro_a_busca_da_cidadania_fical\%5B1\%5D.pdf\&usg =AFQjCNFVKfjMjEVTlp3ooSDC6RiL9FuqeQ $>$. Acesso em: 20 nov. 2017.

ROCHA, Ludiana Carla Braga Façanha; DINIZ, Márcio Augusto de Vasconcelos. A administração púbica e o princípio da confiança legítima. Disponível em: $<$ http://www.egov.ufsc.br/portal/sites/default/files/anexos/32601-39843-1-PB.pdf>. Acesso em: 09 maio 2018.

SALAMA, Bruno Meyerhof. O que é "Direito e Economia"?: Uma introdução à epistemologia da disciplina para o Estudante, o Profissional e o Pesquisador em Direito. Disponível em: < http://direitosp.fgv.br/publicacoes/direito-economia-introducao-epistemologia-disciplina-para-estudante-profissional-pesquis $>$. Acesso em: 20 abr. 2018.

STIGLER, George. Law or Economics? The Journal of Law and Economics, v. 35, n. 2, Oct. 1992.

TÔRRES, Heleno Taveira. Incentivos Fiscais na Constituição e o "Crédito-prêmio de IPI”. In: DIREITO Tributário Atual - 18. São Paulo: Dialética \& Instituto Brasileiro de Direito Tributário, 2005.

TÔRRES, Heleno Taveira. Desenvolvimento, meio ambiente e extrafiscalidade no Brasil. In: Pires, Manuel. Extrafiscalidade. Lisboa: Universidade Lusíada, 2011. 
TORRES, Ricardo Lobo. Os Direitos Humanos e a Tributação. Rio de Janeiro: Renovar, 1995.

Recebido em: 13/07/2018

Aceito em: 28/09/2018 